\title{
Imigraçâo japonesa e engenharia naval: $O$ papel e a importância da Ishikawajima do Brasil
}

\author{
Mariléia Franco Marinho Inoue \\ Thais de Souza Lopes Leal \\ Universidade Federal do Rio de Janeiro
}

\section{Introdução}

A proposta deste ensaio é fomentar um debate a respeito da presença dos imigrantes japoneses, vindos após a II Grande Guerra, para suprir os quadros técnicos da construção naval brasileira, a partir do final da década de 1950. Da mesma forma discutir as possíveis implicaçôes da presença do grande estaleiro, Ishikawajima do Brasil - Estaleiro S. A., primeira filial da secular Ishikawajima Harima fora do Japão.

A relevância desta proposta reforça-se pela constatação surpreendente da inexistência de um estudo sistematizado a respeito dos impactos na Indústria Naval provocados por sua presença, responsável por incontestáveis feitos nas linhas de produção e no conhecimento tecnológico de uma forma mais abrangente. Além disso, repercutem seus efeitos não apenas no próprio campo econômico, mas também no político e social.

Mesmo que de forma breve, resgatamos um pouco da história da engenharia naval no Estado do Rio para a discussão que nos interessa. Destacamos, também, a vinda dos imigrantes japoneses dentro do Plano de Metas do Governo Juscelino Kubitscheck de Oliveira, assim como a instalação e funcionamento do empreendimento da Ponta do Caju, Zona Portuária do Rio de Janeiro, ilustradas na prática da Engenharia Naval com algumas características da gestão da mão-de-obra usada no processo de construção de navios. Ressaltamos o apogeu nos anos do Milagre Brasileiro, o declínio durante o Governo Collor e a extinção da empresa em 1996, deixando um patrimônio expressivo. Tal acervo, em condições 
de ser assumido e de produzir, levou anos para ser novamente cogitado como estratégico para a indústria naval no Estado do Rio de Janeiro.

\section{O estudo sobre os imigrantes japoneses no Estado do Rio de Janeiro}

Este estudo vai ao encontro das necessidades atuais de investigação interdisciplinar, em um grupo de estudos sobre migraçôes, que discute as transformaçôes na paisagem cultural dos deslocamentos humanos, especialmente durante o século XX. Pressupõe que a contemporaneidade traz em sua pauta a crise dos espaços legítimos de representação, a globalização da cultura, fragmentação dos sujeitos sociais e tornam o estudo da memória e das identidades sócio-culturais como temas de extrema relevância. Sua importância se baseia na própria necessidade de revitalização da história da imigração transnacional, pretendendo contribuir com o debate sobre acervos conjugados de fala e imagens. ${ }^{1}$

Pouco relevante numericamente, a imigração japonesa, do ponto de vista qualitativo, destacou-se pela atuação dos seus integrantes em diversos setores da vida de nosso Estado, marcada sobretudo pelo pioneirismo e inovação. A presença japonesa no Estado do Rio de Janeiro, entretanto, registra-se fartamente em várias fontes, antes da imigração oficial marcada pela chegada do Kassato Maru. Ao lado da Legação Japonesa em Petrópolis, que marcava uma presença diplomática, registram-se, também, indivíduos que estavam presentes, desde o século XIX, por conta própria, destacandose comerciantes e industriais, atletas e artistas circenses, cujas apresentações destacavam-se pela destreza, disciplina e força física em espetáculos itinerantes. Destacavam-se, também, no ensino de ginástica, sobretudo na Academia Imperial, à época de Pedro II.

No século XX adensou-se sua presença, como imigrantes empreendedores na agricultura do interior do Estado, na Escola Industrial de Pesca, na extração salineira, no melhoramento de espécies agrícolas como goiaba, tomate, pimentão, quiabo, etc. Nas obras de Engenharia Civil destacou-se a empresa Yamagata Engenharia, responsável pela execução de várias obras públicas de envergadura não apenas no Estado do Rio de Janeiro, mas também em São Paulo e Minas Gerais.

No tocante aos japoneses que chegaram ao Brasil depois da II Guerra (imigrantes novos), ${ }^{2}$ estes caracterizavam-se por constituir um grupo conscientizado, que não retornaria ao Japão e cuja missão era servir bem ao país receptor, porque esta era a forma de melhor servirem a terra onde nasceram. Estes novos imigrantes destinavam-se, sobretudo, à formação 
de quadros técnicos para a agricultura, através da Cooperativa Cotia para todo o Brasil e, da mesma forma, para a indústria naval, experiência unicamente viabilizada no Estado do Rio de Janeiro, à qual daremos destaque.

\section{A Indústria Naval do Estado do Rio de Janeiro e sua importância no Brasil}

As características navegáveis do Brasil, a possibilidade de exploração de suas riquezas, aliada à experiência dos portugueses, provocaram, em especial na região fluminense, uma marcada atuação na indústria naval no Brasil colonial.

Portugal tinha forte tradição marítima e foi pioneiro nas tecnologias de navegação em alto mar e na construção naval, o que lhes permitia aproveitar a abundância e excelência das madeiras brasileiras, além da mão-de-obra indígena.

A região do Rio de Janeiro, desde os tempos coloniais, destacou-se com inegável liderança no setor. No ano de 1662 foi construído o galeão Padre Eterno, o maior navio do mundo na época. O Arsenal de Marinha do Rio de Janeiro foi fundado em $1763,{ }^{3}$ no qual se construiu a nau S. Sebastiāo, de 1767.

De 1840 em diante sucederam-se: implantação de novas oficinas, modernização e ampliação do Arsenal do Rio de Janeiro, mudanças ensejadas pelo retorno dos brasileiros que realizaram o primeiro curso formal de Engenharia Naval, na Europa, entre eles Napoleão Level, Trajano de Carvalho e Carlos Braconot. Abriu-se então uma fase de construções pioneiras: o navio à hélice em 1852; o primeiro encouraçado de fabricação brasileira, em 1853; o primeiro navio construído inteiramente de metal em 1883; além do cruzador Tamandaré de 4.573 toneladas, grande feito em 1890, ultrapassado somente em 1962 em dimensões. Na época, o Arsenal do Rio de Janeiro comparou-se aos mais modernos centros de Engenharia Naval da Europa e no período de 1825 a 1890 produziu 46 embarcações.

A Companhia de Fundição e o Estaleiro da Ponta D’Areia, em Niterói, Rio de Janeiro, constituíram um marco, primeiro grande estaleiro do Brasil, fundado em 1845, por iniciativa particular do Barão de Mauá, empreendedor e precursor da indústria no país. $\mathrm{O}$ empreendimento foi estimulado pelo aumento da taxação dos produtos importados, pelas facilidades de importação de ferro e pela garantia de encomendas do governo. ${ }^{4}$ 
Em 1850 foi criado o Estaleiro Só, no Rio Grande do Sul e seis anos depois se fundou o Estaleiro Caneco, no Rio de Janeiro, onde também tinham sido criadas as Oficinas Lage \& Irmãos, na Ilha das Enxadas (1832).

Tentativas de regulamentação do transporte interno e transoceânico, de distribuição de concessões e de apoio em subvenções expandiram-se. O surgimento da Companhia Transoceânica de Navegação, em 1890, empresariada pelo Lloyd Brasileiro e da Companhia de Navegação Costeira, em 1891, mostram a ampliação do setor.

Os esforços, no entanto, não consolidaram uma política efetiva para o setor, que a partir da segunda metade dos anos de 1890 começou a enfrentar uma fase de marasmo e atrofiamento. Diversas iniciativas buscaram modificar esse quadro, como o caso do Plano Naval Wenceslau Braz, de apoio à construção naval, melhoria dos estaleiros e a reforma dos Arsenais, formulado pelo industrial brasileiro Henrique Lage em conjunto com o engenheiro naval Thiers Fleming.

Ainda que se registrem algumas iniciativas como a construção de três navios na Ilha do Viana, lançados ao mar nos anos de 1919 e 1920 onde estava o Estaleiro de Henrique Lage: dois navios mercantes com $3.500 \mathrm{t}$ e o pequeno petroleiro 340-B, de 1500 t, primeiro navio construído por encomenda para exportação, comprado pelo governo argentino, ${ }^{5}$ as propostas para o desenvolvimento do setor não se efetivaram e o quadro de decadência se arrastaria pelas décadas subseqüentes.

A despeito das duas ajudas do Banco do Brasil para pagamento de trabalhadores em greve, o estaleiro de Henrique Lage não conseguiu sucesso, teve contratos e encomendas suspensos. Com a Revolução de 30 Lage foi preso e somente retornou à vida política em 1935 como deputado e apresentou o Projeto de Proteção à Construção Naval, para o qual não recebeu apoio.

Somente em 1937, com a construção do novo Arsenal de Marinha da Ilha das Cobras, atual Arsenal de Marinha do Rio de Janeiro, retomou-se a construção naval no Brasil. ${ }^{6}$ A década de 40 foi marcada pela encampação de várias empresas de navegação devido à criação da empresa de Serviços de Navegação da Bacia do Prata S. A., de propriedade do governo, e pela instalação da Comissão Marinha Mercante, autarquia federal ligada ao Ministério dos Transportes, com o objetivo de disciplinar a navegação. ${ }^{7}$

Apesar dos esforços a defasagem técnica da indústria naval brasileira em relação à produção internacional de navios era grande e se estendeu 
até o final da década de 1950. As políticas nacionais de transporte, vigentes desde o início do século vinte, sofreriam novo redimensionamento através do Plano de Metas, com uma política específica para o Setor da Indústria Naval a ser estudado no próximo item.

A presença do imigrante japonês, na primeira metade do século passado, é registrada desde 1909, quando mais de vinte japoneses trabalhavam na proteção dos armazéns e na manutenção de navios no interior da Baía de Guanabara.

O local com maior número de japoneses era o Estaleiro Lage, pois o Ministro Japonês Sadatsuchi Uchida era amigo de Antônio Lage, ${ }^{8}$ empresário de carvão, estivas e pequenas embarcações, comendador e grande empresário que comprou a Ilha do Viana em 1882. Lage conhecia Yamagata, empresário do mesmo setor no Japão, que imigrou para o Brasil e fixou-se no Rio de Janeiro, antes de 1908, conseqüentemente, antes do Kassato Maru, marco do início da imigração oficial japonesa no Brasil.

Ainda se conserva, entre a Ilha do Viana e a de Santa Cruz, uma pequena ponte de $5 \mathrm{~m}$ de comprimento e $2 \mathrm{~m}$ de largura, à esquerda, onde fica uma pequena cabine, posto de vigia que foi ocupado por Saburo Kumabe. ${ }^{9}$ Este ilustre personagem pioneiro da imigração era um juiz, vindo de Kumamoto, do Japão para Macaé, em 1906, cujo sonho de formar um Núcleo colonial fracassou ante a política de imigração de massa para São Paulo. ${ }^{10}$

São abundantes as evidências sobre a Gamboa Ryouzampaku, ${ }^{11}$, fornecedora de mão-de-obra, para a indústria naval, intermediada por Yamagata: uma pensão onde ficavam, além dos imigrantes operários japoneses, inclusive órfãos (quatro do Orfanato de Okayama e quatro do Asilo da Cidade de Tóquio), ${ }^{12}$ alguns "chineses de coragem e aventureiros". ${ }^{13}$

E, finalmente, é importante recuperar o registro de que, em 1912, Antonio Lages despediu 12 japoneses, devido a uma greve por salários e ao protesto de outros funcionários que moravam na parte mais elevada da Ilha de Santa Cruz, cujas mulheres avistaram três japoneses, funcionários do estaleiro, tomando banho na praia sem roupa. ${ }^{14}$

\section{O Plano de Metas do Governo Kubitscheck para o Setor Naval e a Criação da ISHIBRÁS}

Em Janeiro de 1956, Juscelino Kubitschek de Oliveira foi eleito Presidente da República Federativa do Brasil, com a bandeira do Progresso 


\section{Dôssie Imigração}

de 50 anos em cinco e com o Plano de Metas, um projeto de desenvolvimento econômico de cinco anos, que previa a implantação de novas indústrias de base, como siderurgia, indústria automobilística e construção naval.

Embora a ênfase de seu governo tenha sido o setor rodoviário, em especial a indústria automobilística, o Plano tinha referências à indústria naval e ao seu potencial de alocação de mão de obra. Dentre as metas pode-se destacar: No 10 - Portos e Dragagem; No 11 - Marinha Mercante e No 28 - Construção naval, com recursos prioritários destinados ao setor, tendo como fonte de financiamento o Banco Nacional de Desenvolvimento Econômico (BNDE), hoje Banco Nacional de Desenvolvimento Econômico e Social (BNDES).

Em 1956, um relatório do Ministério da Viação e Obras Públicas indicava baixos índices de desempenho da Marinha Mercante. No transporte de cargas do comércio exterior, o Brasil possuía somente 20 navios, construídos no período de 1947-1948; a frota de cabotagem contava com navios com mais de 20 anos de uso, além de gastar-se muito com o fretamento de navios estrangeiros.

O documento do Ministério da Viação e Obras Públicas propunha uma reforma nas bases financeiras da indústria de transporte por água estatal e privada - com a criação da Taxa de Renovação da Marinha Mercante e do Fundo da Marinha Mercante. Os recursos gerados seriam responsabilidade da Comissão de Marinha Mercante e a Lei 3.381 de abril de 1958, criadora do Fundo da Marinha Mercante, impulsionou de fato a indústria naval no Brasil, pois objetivava evitar a importação de embarcaçōes e diminuir os custos com o fretamento de navios estrangeiros, incitar a renovação, expansão e recuperação da frota mercante nacional, garantir encomendas à produção da indústria de construção naval e estimular a exportação de embarcações.

No Plano de Metas, o setor naval incluía indústrias de grande porte do mundo inteiro, instaladas no Brasil, em especial entre os municípios do Rio de Janeiro e Niterói. No ano de 1958, foi criado, também, o Grupo Executivo de Indústria da Construção Naval (GEICON). A Comissão de Marinha Mercante (CMM) seria substituída, em 1969, pela Superintendência Nacional da Marinha Mercante (SUNAMAM).

A Comissão foi constituída no Ministério dos Transportes visando à construção de uma frota mercante nacional, que pudesse substituir os navios estrangeiros no transporte dos produtos importados e exportados. 
A GEICON elaborava normas para projetos de estaleiros, dificultava a compra de navios estrangeiros e estimulava a importação de equipamentos necessários à produção de navios. Em 1959 o Grupo propiciou a aprovação de 11 projetos empresarias.

Desses projetos, apenas seis, de fato, concretizaram-se: os dos Estaleiros Mauá, que receberam o maior financiamento do BNDE; a Emaq e Caneco, que só seriam ampliados; o Ishikawajima e Verolme, o primeiro de origem japonesa e o segundo holandesa, seriam construídos com apoio do capital estrangeiro. Um novo ciclo foi inaugurado no país com a construção e ampliação dos estaleiros, a importação e a instalação de equipamentos, o recrutamento de engenheiros e técnicos e os 33 treinamentos de mão-de-obra. Logo no início de 1960, as encomendas foram atendidas, com a entrega das primeiras embarcações. Desta forma, implantaram-se no Brasil estaleiros operados por subsidiárias de grandes empresas estrangeiras de construção naval.

Desde a década de 1950, a Ishikawajima Harima, com cem anos de experiência no setor, sediada no Japão, já vinha construindo navios para o Brasil, ${ }^{15}$ Como os Navios Sirius NH21 e o Nhi Canopus - H22 ${ }^{16}$ para a Marinha de Guerra e um navio tanque para a Petrobrás, entregue em 1959 para a subsidiária FRONAPE.

O Presidente do Grupo japonês, Toshio Doko, visitou o Brasil e várias delegações japonesas analisaram o mercado e estudaram a possibilidade da Ishikawajima Harima Heavy Industries Co. Ltd. (IHI) ${ }^{17}$ implantar no Rio de Janeiro a primeira filial fora do Japão, subsidiária do grupo japonês.

O projeto da Ishikawajima do Brasil Estaleiros S. A. foi aprovado em novembro de 1958 e ficou conhecido como ISHIBRÁS. A nova e promissora empresa constituiu-se em janeiro de 1959 e recebeu terrenos na Ponta do Caju, em São Cristóvão, com partes a serem aterradas. Sua sede ficou localizada à Av. Presidente Antonio Carlos, 607, sobreloja, onde se situava a Ishikawajima Indústria e Comércio, com a sigla de ISHICOM, que se estabelecera no Brasil anos antes, apenas para comercializar a venda de navios.

A Ishikawajima-Harima Heavy Industries, ${ }^{18}$ foi considerada a segunda maior indústria do Japão, atrás apenas da gigante Mitsubishi Heavy Industries. Atualmente chamada de IHI Corporation, envolvida com a tecnologia de ponta, incluindo energia nuclear, super condutividade, lasers, 


\section{Dôssie Imigração}

compostos avançados e materiais cerâmicos. Sua ação tornou-se mais diversificada, principalmente, a partir da retração da indústria naval em âmbito mundial. Com os antecedentes da 2a Guerra Mundial (19391945), a demanda pelo desenvolvimento de novos produtos da Ishikawajima aumentou e a subsidiária Ishikawajima Shibaura Turbine Company começou a operar em 1936.

No pós-guerra, as indústrias japonesas conseguiram uma recuperação relativamente rápida e a Ishikawajima ampliou seu campo de atuação, abrindo sua primeira filial estrangeira, em 1959, no Brasil, com a cerimônia de lançamento da pedra fundamental do novo estaleiro tendo lugar em 13 de dezembro de 1958, com a presença do Presidente da República Juscelino Kubitschek. Exatamente um ano depois a companhia iniciou a construção do cargueiro Volta Redonda, de 5.800 DWT, com seu lançamento ao mar dando-se em 30 de janeiro de 1961.

A foto a seguir é de Kazushi Sugahara, vindo pelo América Maru, em 23 de abril de 1959, um dos imigrantes da pós Segunsda Guerra que compôs os quadros técnicos na Engenharia Naval brasileira. Sugahara trabalhou na ISHIBRÁS, percorrendo todo Brasil até sua aposentadoria. Residente em Niterói, onde o entrevistamos, é ativo na divulgação do gateboll no Brasil. Para ele, é nítida a idéia de que a empresa japonesa difundia novas tecnologias gerenciais, não somente na indústria naval. $\mathrm{O}$ trabalho realizado com afinco e as novas tecnologias eram idéias difundidas a respeito dos japoneses pelo Brasil afora. A ISHIBRÁS, através dos imigrantes novos e dos antigos imigrantes e seus filhos, tornou-se a expressão de uma determinada maneira de encarar o processo de trabalho, educação continuada e uma base difusora de novas tecnologias.

Os padrões japoneses de gerenciamento e administração orientavam a ascensão dentro da empresa. ${ }^{19}$ A primeira grande obra daquele estaleiro foi o dique seco, ${ }^{20}$ que ainda se utiliza atualmente. Na Ponta do Caju eram preparados desde os projetos e desenhos - na sala de riscos - até a limpeza das chapas de aço com jatos de areia e a pintura. Os metais eram cortados com as tecnologias mais avançadas, e soldados em enormes blocos de chapas de aço, levadas por pontes-rolantes para dentro do dique seco para a montagem final dos cascos do navio. As pontes rolantes e muitos aparelhos de solda elétrica eram vistos por toda oficina. Começou, assim, a construção de navios de 6.000, 10.000 e 30.000 toneladas deadweit. 
Figura 01 - Imigrantes japoneses componentes dos quadros técnicos da Engenharia Naval da ISHIBRÁS: Kazushi Sugahara

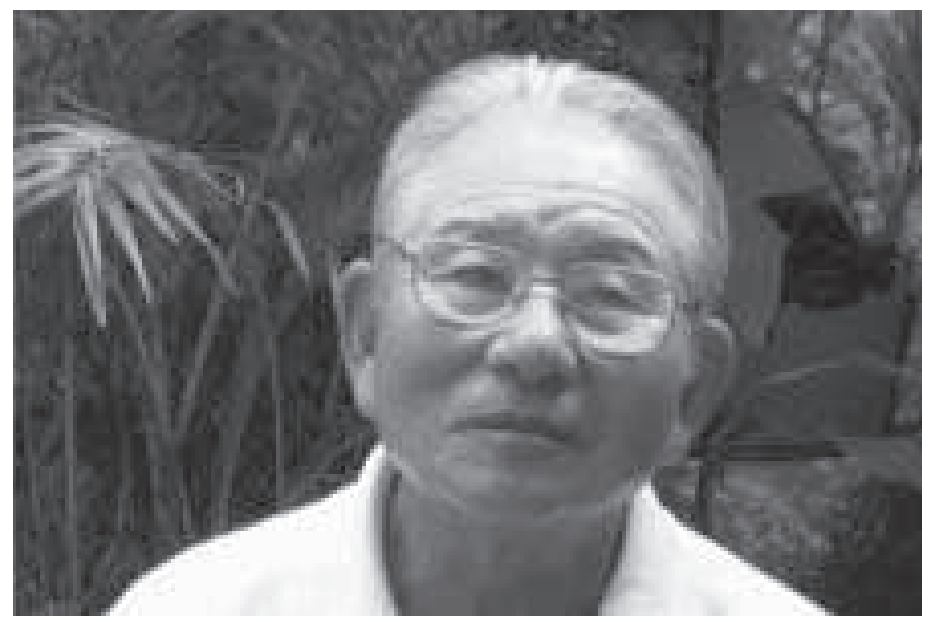

K. Sugahara em Niterói, durante entrevista concedida á pesquisadora em 2009 Um engenheiro dos quadros da ISHIBRÁS. Acervo Mariléia Inoue, 2009

Os mesmos padrōes de gerenciamento e administração permitiram, ainda, a construção de diques flutuante ${ }^{21}$ e plataformas continentais, para perfuração e extração de petróleo no fundo do mar e por fim, os navios gigantes. ${ }^{22} \mathrm{O}$ estaleiro era visitado por políticos como Carlos Lacerda e líderes da sociedade civil, que vinham fazer ali seus comícios, já que os metalúrgicos da área naval eram considerados estrategicamente importantes no conjunto dos trabalhadores, pelo menos até 1964, quando as greves aumentaram gradativamente.

O grande arranque da atuação da ISHIBRAS aconteceu dentro do período de desenvolvimento econômico, conhecido como milagre brasileiro, das décadas de 1970 e 1980 . Havia importantes diferenciais até então não conhecidos pela sociedade brasileira: a avançada tecnologia, educação dos funcionários e relações trabalhistas de garantia de assistência social e segurança de trabalho para os empregados e seus familiares.

A Superintendência Nacional de Marinha Mercante, SUNAMAN, do Ministério de Transporte, apresentou os planos de construção de navio de grande porte, que foram respondidos em janeiro de 1974, com a inauguração do segundo dique de construção, com capacidade para a construção de navios de até 400.000 TDW. O dique principal era o maior 


\section{Dôssie Imigração}

da América do Sul para construção dos grandes navios, de até 280 mil toneladas, e o dique menor para construção dos demais navios.

A ISHIBRÁS construiu desde navios para a Marinha do Brasil até navios para o Exterior, de tamanhos e finalidades diferentes, como foi o caso do Navio Tanque Marajo, ${ }^{23}$ construído pelo estaleiro da ponta do Caju, em meados da década de 1960, e o Navio Tanque Almirante Gastão $M o t t a,{ }^{24}$ outro navio tanque que, tal qual o anterior, foi construído no mesmo local, na década de 1980. Foram também construídos quatro navios mínero-petroleiros de 277.000 DWT e, a partir de 1975, durante quatro anos consecutivos, a ISHIBRÁS ocupou o primeiro lugar no ranking latinoamericano da construção naval. Em face da crise da economia mundial, a empresa demonstrou, tanto na quantidade como na qualidade, resultados muito superiores aos de seus concorrentes.

$\mathrm{Na}$ década de 80 houve uma automação no transporte naval: equipamentos mais modernos e uma série de requisitos que possibilitou que o Brasil construísse oito navios da classe Piranha, de 18.000 t, entregues nesta ordem: Diva, ${ }^{25}$ Dilya, Nilza, Maisa, Marta, Norma, Nara, Neusa, todos encomendados em 09 de janeiro de 1978 pelo armador Petróleo Brasileiro S.A. - Petrobrás/Frota Nacional de Petroleiros - FRONAPE, finalizando o processo de substituição dos navios da classe Dom João e Itaparica, construídos nos anos 60, para serem utilizados no transporte de produtos claros em rotas de cabotagem, registrados no Rio de Janeiro e até hoje em atividade na TRANSPETRO.

Foram comprados no Japão mais três navios de gás modernos, pois os da Classe Guarujá, navios de gás, apresentavam-se bastante antiquados. A FRONAPE, que já operava navios ore-oil, super graneleiros, passaria a operar o dobro de navios que ela possuía. Substituiu praticamente, a frota que foi então incorporada e reduziu o afretamento em time-charter ao atual único navio remanescente, o NV Explorer, um ULCC3 de 400.000 $\mathrm{t}$ ainda afretado até 1990 . Todos os outros foram substituídos por navios próprios. Mesmo com os 19 navios, porém, a frota brasileira ainda não era auto-suficiente na cabotagem, embora tenha ficado em uma situação cômoda para continuar com encomendas de reposição e ampliação, mantendo uma frota adequadamente dimensionada para as necessidades do país. ${ }^{26}$ 


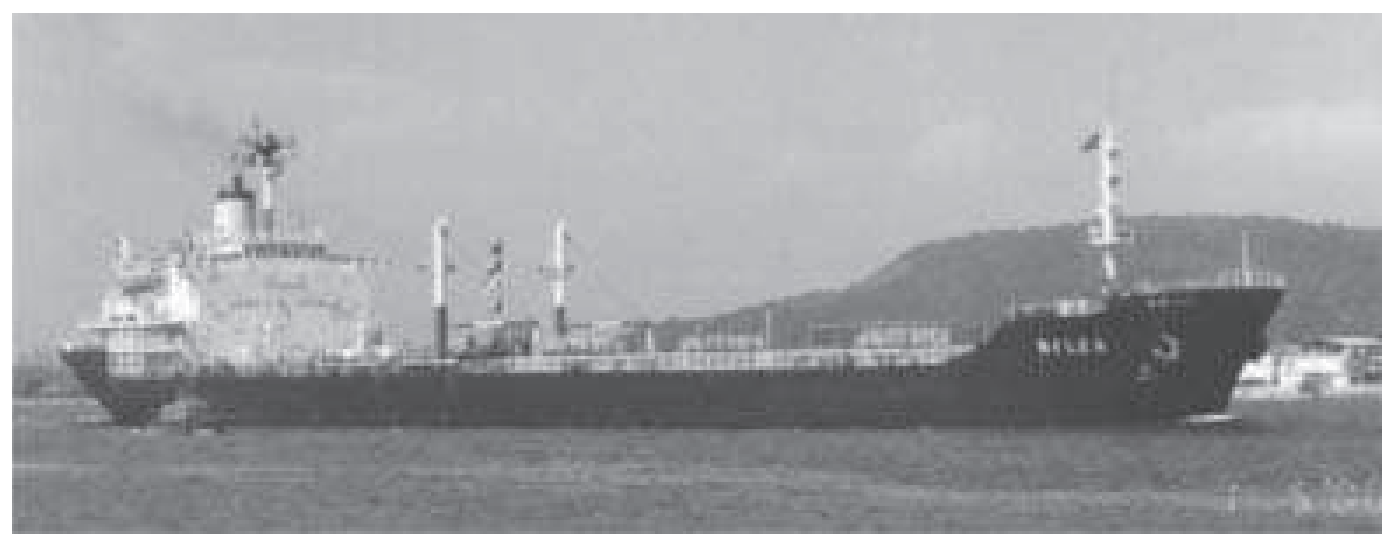

Fonte: Navio Nilza, terceiro a ser entregue à FRONAPE, disponível na Internet, no site http:// www.naviosmercantesbrasileiros.hpg.ig.com.br/nt_diva.htm, acessado em 22 de maio de 2010 .

Existia uma explicação, por parte do Governo, para sua retirada abrupta do apoio direto à indústria naval, visto que, até então, mantinha o incentivo à indústria naval por motivos atribuídos a circunstâncias

especiais [que] levaram o país a uma situação em que só os armadores estatais estavam em condiçōes de encomendar. Todos os estaleiros construíram para a exportação. /.../ A Ishikawajima construiu um grande porta-containers para o grupo do Tung, apesar de ter havido a incorporação do navio, houve encomendas para o estrangeiro. A Verolme, o Caneco e o Emaq também construíram navios para exportação e não cumpriram os prazos das encomendas, devido ao problema dos choques do petróleo, aí o Brasil perdeu credibilidade. [...] Daí terem surgido algumas não-entregas e compras pelo Lloyd". ${ }^{27}$

A FRONAPE sempre fora uma unidade operativa da Petrobrás, pertencente ao Departamento de Transportes. Ela era, realmente, singular, peculiar, única, concentrando, praticamente, todos os 4.300 marítimos realmente marítimos - da Petrobrás. Mas a FRONAPE era uma das atividades do monopólio citadas na lei. E tem sido um princípio aceito e mantido pela Petrobrás que toda a atividade monopolista fica com a holding Petrobrás, não sendo passada para nenhuma subsidiária. ${ }^{28}$

Em 1983, a empresa recebeu uma encomenda de dois navios petroleiros de 300.000 DWT. Nessa época a ISHIBRÁS estava em seu apogeu: o número de empregados passava de sete mil (julho de 1980) e tinha como firmas subsidiárias a ISHITEC, ITAIPUAM, ASTECS, PROTUBO, TERABRAS, RENAVE e IHB. O sucesso da ISHIBRÁS acompanhou o desenvolvimento econômico do Brasil no mesmo período, sob o comando 


\section{Dôssie Imigração}

do então presidente Orlando Barbosa. Dessa forma, o empreendimento cresceu no conceito dos círculos políticos e econômicos do Brasil, o que contribuiu para a projeção internacional do Japão.

A ISHIBRÁS, em colaboração com a Ishikawajima Harima assegurava a nacionalização e desenvolvia a engenharia dos grandes projetos governamentais e privados, não somente da engenharia naval. $\mathrm{O}$ controle de qualidade na fabricação dos vasos de pressão detinha os selos de código ASME, U e U-2 e era um dos poucos fabricantes laureados na América do Sul.

Neste sentido, a construção naval brasileira era a segunda maior indústria do mundo, naquela modalidade, com mais de quarenta mil empregados e exportação para Inglaterra, França, Alemanha, Grécia e Estados Unidos. No país foram construídos os dois maiores navios da frota brasileira: os supergraneleiros ${ }^{29}$ $T_{i j u c a^{30}}$ e Docedjord, de 305 toneladas de capacidade, que figuram entre as cem maiores obras de Engenharia do Brasil. Os dois navios tinham 332 metros de comprimento, na ocasião, recorde mundial de navios de sua classe. ${ }^{31}$ Hoje a Companhia Vale do Rio Doce freta, por contrato fixo, também o $B W F^{\prime} j o r d{ }^{22}$ de 1986 com 310, 698 tons, e o $B W V i k^{33}$ de 1987 com 310, 698 tons, por meio de contratos bilionários com os Noruegueses da BW (Bergesen) .

Figura 03 - O Doce-djord, maior navio de sua categoria construido pela ISHIBRAS na década de 80

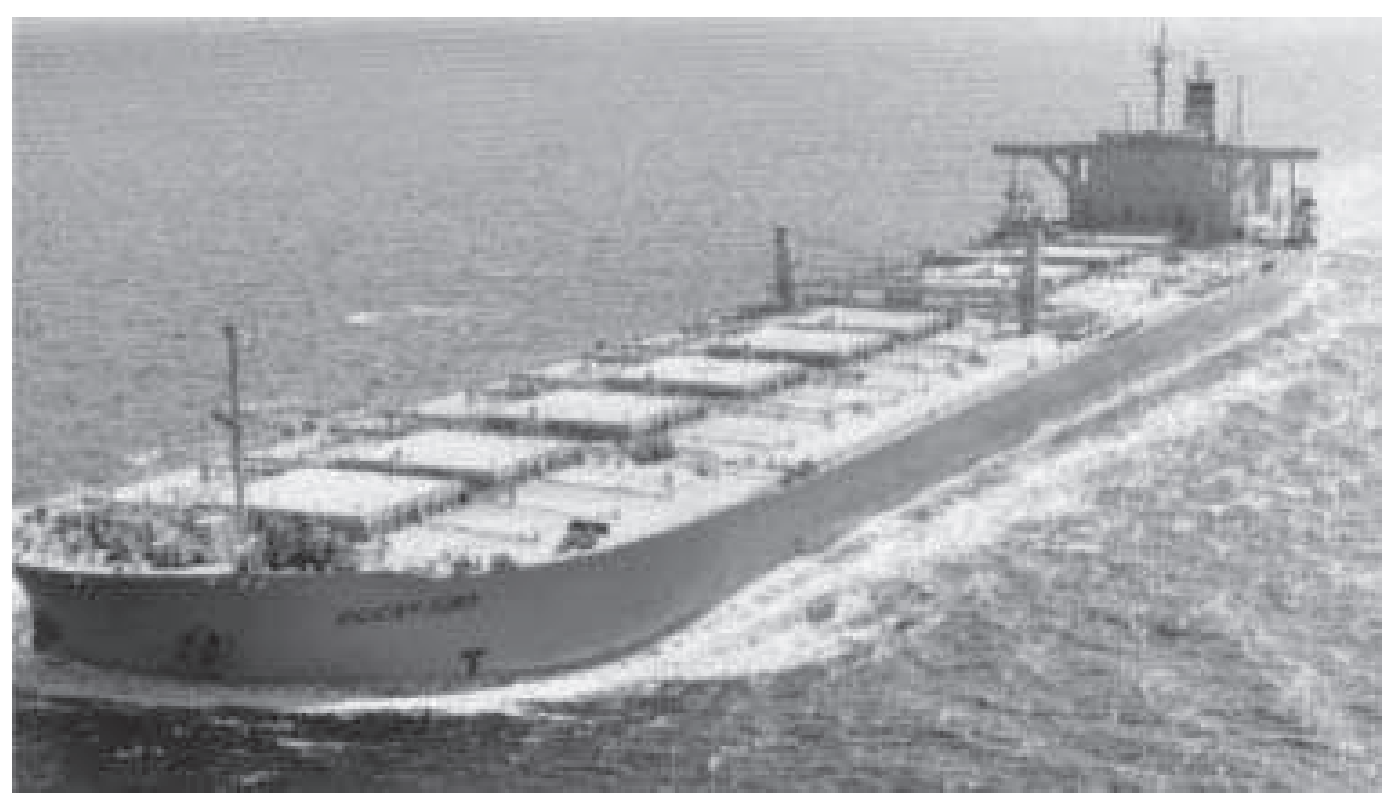

Fonte: Em destaque o Docedjord um dos dois grandes graneleiros construídos pela Ishikawajima. Disponível em http://www.pbase.com/osmund/image/58932188, acessado em 30 de maio de 2010. 
Para efeitos de resgate da memória, encontramos, durante a pesquisa sobre a construção do navio acima ilustrado, a descrição em um jornal, editado em maio de 1986, pela Escola de Oficiais da Marinha Mercante, observaçôes a respeito da construção do navio, sob o título "D. Marly batiza o maior mínero-petroleiro do Mundo", onde o editor menciona que, em dezembro de 1985, a esposa do Presidente José Sarney batizou o maior petroleiro do mundo, no estaleiro Inhaúma, pertencente à ISHIBRÁS.

O que tem destaque na notícia é o espanto quanto à grandeza do navio, pois o editor fornece ao leitor comparações do navio com monumentos conhecidos, como maneira de possibilitar-lhe formas mais simples de medir sua grandeza: o maior navio construído até então em sua categoria:

O maior navio de seu tipo construído em todo o mundo, o mineropetroleiro Docefjord, de 305 mil toneladas de porte bruto, foi batizado no mês de dezembro passado tendo como madrinha a Sra. Marly Sarney, esposa do Presidente da República. A solenidade foi realizada no estaleiro Inhaúma, da Ishibrás, que o construiu por encomenda da Wilsea Shipping Inc., uma empresa formada por joint venture, em bases 50/50, pela Vale do Rio Doce Navegação S/ A Docenave e o armador norueguês Willhemsen. O Docefjord tem um comprimento de 332 metros, 32 metros a mais do que a Torre Eiffel, de Paris, em altura e um convés de 17.2 metros quadrados [onde] poderiam ser marcados dois campos de futebol das dimensões do Maracanã e ainda sobrariam 160 metros. $^{34}$

A Ishikawajima não se limitou somente a fabricar grandes navios e diques. Nesse sentido, pelo seu pioneirismo, ainda tem seus processos de fabricação como referência para aulas de hidromecânica, como é o caso da comporta vagão da Usina Hidrelétrica de Paulo Afonso IV (CHESF), no rio São Francisco, projetada pela Ishikawajima do Brasil Estaleiros S/ A, em 1978.

É interessante salientar que a ISHIBRAS, em termos de processo de trabalho, trouxe práticas presentes nas indústrias japonesas, inerentes ao toyotismo, como: círculos de qualidade, gestão de recursos humanos, etc. A ginástica coletiva, por exemplo, era uma prática saudável para os homens que executavam as obras arriscadas da construção de navios, que exigiam extrema atenção e perfeito equilíbrio psicológico.

A empresa tinha um enfoque de educação continuada para seus funcionários. Ao serem contratados, especialmente engenheiros brasileiros, estes iam estagiar na matriz no Japão. O objetivo era técnico-profissional, 
mas também visava à familiarização com a política e a filosofia de recursos humanos no Japão, onde existia a concepção de o emprego vitalício, sendo a fidelidade considerada uma virtude do empregado com relação à sua empresa empregadora.

Foi uma época fecunda, na qual se valorizava o ensino ministrado no Japão. Quando os estagiários brasileiros regressavam do Japão, tinham melhores possibilidades de emprego, graças aos conhecimentos ali adquiridos. A ISHIBRAS, inclusive, ganhou a reputação de ser um importante centro de formação de novos técnicos, de maneira que Orlando Barbosa a chamava de ISHICOLA. ${ }^{35}$

Outro elemento importante era a concepção de pertencimento à empresa por parte de seus empregados, que era incentivada por diversas atividades sociais: nas festas Juninas, no Natal e nas cerimônias de lançamento de navios, para as quais eram convidados os funcionários e suas famílias.

A ISHIBRAS empregou muitos trabalhadores brasileiros, assim como japoneses chegados ao Brasil como imigrantes destinados a outras áreas e, naturalmente, seus descendentes (nikkeis).

As atividades da Ishikawajima do Brasil - Estaleiros S.A. deixaram, também, suas marcas no tecido social. Além de propiciar a dinamização da Câmara de Comércio e Indústria Japonesa, instalada no município do Rio de Janeiro, a concentração de operários e técnicos especializados de origem japonesa estimulou movimentos associativos, como o fortalecimento da Associação Nikkei do Rio de Janeiro, que difundiu a cultura nipônica e também permitiu enraizamento dos imigrantes em alguns bairros da zona sul do Rio de Janeiro, como Glória, Flamengo e Laranjeiras, e, na zona oeste, no bairro de Campo Grande.

\section{O declínio e extinção da Ishikawajima do Brasil Estaleiros $S A$}

Entre as décadas de 1930 e 1970, o Brasil foi uma das economias mais dinâmicas do mundo, ${ }^{36}$ apesar das características estruturais de desenvolvimento e produção por setor, caracterizadas por atividade desiguais e heterogeneidade na estrutura produtiva.

Do início da década de 1960 até o final da década de 1970, a indústria naval experimentou um processo de ascensão, a despeito dos problemas existentes. A importância deste setor foi reconhecida, também, internacionalmente e o Brasil alcançou, no final da década de 70, o segundo lugar em volume de encomendas, perdendo apenas para o Japão, conforme consta do Lloyd's Register do Brasil Ltda. 
Tal panorama mundial foi estimulado pelos efeitos da crise do petróleo, cujos reflexos chegariam com mais força ao Brasil na década de 1980, quando também se encerrava o II PCN e seu ciclo de encomendas.

As crises do petróleo e da dívida externa foram apontadas como fatores de interrupção das medidas para o desenvolvimento de atividades de Engenharia Naval até então crescentes. O corte drástico das oportunidades geradas através de investimentos governamentais paralisou o setor naval e estancou o desenvolvimento econômico nos anos de 1980. A paralisação teve implicações significativas na vida social e econômica do país, pois a indústria naval desenvolvera-se de maneira fortemente atrelada ao Estado, dependente não só do financiamento da produção como também da absorção da demanda produzida.

Nesse cenário, de fim do II PCN, crise do petróleo e dívida externa, os principais armadores nacionais, a Petrobrás e a Vale do Rio Doce, deixaram de investir no setor e as medidas de contenção de gastos, como a extinção do subsídio a fundo perdido para os estaleiros, a diminuição repentina e indistinta do prazo de financiamento dos navios (de 15 para 10 anos) foram medidas duras por parte do governo brasileiro. Diante disto, a SUNAMAN deu seu aval aos estaleiros para transaçôes financeiras com bancos nacionais e estrangeiros para fazer face aos contratos e encomendas estabelecidos de antemão. ${ }^{37}$

A partir de meados da década de 1980, o Brasil sofreu os efeitos da crise econômica mundial, que impôs graves dificuldades às indústrias nacionais. Muitas empresas de transporte marítimo cessaram suas atividades e, no Japão, a economia sofreu forte retração pela super valorização da moeda japonesa, reduzindo as atividades das empresas japonesas no Brasil. Sucedeu-se uma quebra da cadeia produtiva brasileira na década de 1990, como decorrência de uma série de políticas econômicas de choque para combater a inflação, o congelamento de todos os depósitos bancários do Banco Central, o déficit público e as diretrizes de importação e exportação do governo do Presidente Fernando Collor. A abolição do subsídio direto governamental para nova construção de navios e a dissolução da SUNAMAM foram definitivas para o abandono de todos os planos relativos à construção naval. O Estado do Rio de Janeiro, em especial, recebeu um choque econômico e social de grande porte, porque o setor naval era um forte fator de desenvolvimento. Em 1981, o Governo Federal lançou as bases do Plano Permanente da 
Construção Naval (PPCN) para dar continuidade ao desenvolvimento do setor naval, no entanto, esse foi um plano que não deslanchou.

A dívida dos estaleiros, englobando as empresas Mauá, Caneco, Ebin, Emaq, Ishikawajima, Maclaren e Verolme, era estimada em US\$ 580 milhōes, contraída, em cerca de $1 / 4$ do seu valor, em bancos estrangeiros. A Comissão de Inquérito Administrativo estudou essa dívida e as investigações indicaram corrupção do Governo Federal e de empresários do setor naval. Verificaram a existência de documentos ilegais nas contas dos estaleiros com a SUNAMAM: os cofres públicos haviam sido prejudicados em proveito das empresas, porque os contratos foram encarecidos e os cálculos de correção feitos sobre o total dos contratos (e não sobre a parcela efetivamente mais cara) - o que onerava a União; as duplicatas dos estaleiros teriam sido emitidas fora do prazo, de forma que os faturamentos pudessem ser antecipados em benefício das empresas particulares; A SUNAMAM, dessa maneira, comprometera-se, profundamente, com os estaleiros do setor.

Mesmo os dois maiores estaleiros do Brasil na época, o Verolme e o Ishikawajima, de capital estrangeiro, não conseguiram sair ilesos da crise e demitiram centenas de funcionários. O empresário Paulo Ferraz, dono do Estaleiro Mauá, de Niterói, presidente do Sindicato Nacional da Indústria da Construção Naval (SINAVAL) pressionado pela situação suicidou-se.

Em 1985 o Escândalo SUNAMAM continuava sendo investigado quando mais uma moratória foi pactuada. O declínio da produção dos estaleiros já era visível em todo o país.

A crise da indústria naval, com denúncias de corrupção, foi divulgada amplamente, envolvendo todos os estaleiros, sem preocupações com menções específicas ao grau ou às formas de envolvimento de cada um com todo o processo.

Os efeitos da crise do Petróleo e da dívida externa brasileira seriam sentidos com impacto profundo e a produção naval, em queda, provocaria inúmeras demissões. Criou-se a Comissão de Tomada de Contas na Superintendência e, constatados os procedimentos irregulares envolvendo os estaleiros, houve suspensão do pagamento das cartas de crédito aos 38 bancos brasileiros e estrangeiros. A SUNAMAM foi extinta em 1983 pelo Decreto-lei 2.035 e a gestão financeira dos contratos vigentes ficou sob responsabilidade do BNDES. ${ }^{38}$ 
O cenário de crise e as denúncias de corrupção arrefeceram a dinâmica $\mathrm{da}$ indústria naval e afastaram investidores nacionais e internacionais, como no caso do grupo japonês, detentor do estaleiro ISHIBRAS, primeira subsidiária da companhia Ishikawajima-Harima Heavy Industries, que acabou por abandonar as atividades no Brasil.

O Estaleiro Ishikawajima do Brasil, como vimos no transcorrer desse artigo, foi um dos principais estaleiros do país. Ele ocupava uma área de cerca de 450 mil metros quadrados, detinha o maior dique seco da América Latina e empregava milhares de trabalhadores. Para além dos significados e das experiências deixadas nas vidas dos próprios trabalhadores, deixou também um grande patrimônio instalado na Zona Oeste, Bairro de Campo Grande, hoje sob o controle da Companhia Siderúrgica Nacional, e na Ponta do Caju, propriedade particular arrendada à Petrobrás ${ }^{39}$ por 20 anos, que atualmente insere-se no esforço de alavancar a indústria naval no país. ${ }^{40}$

\section{A Guisa de Consideraçôes Finais}

Esse texto propôs-se a ressaltar como a ausência e/ou as descontinuidades das políticas públicas, no que diz respeito à indústria naval, foram responsáveis pela constante dependência de embarcações estrangeiras, em que, pese o avanço tecnológico e crescimento da frota brasileira, foi visível em vários períodos.

Da mesma forma propôs-se a sistematizar os dados sobre a presença da Ishikawajima do Brasil - Estaleiro S. A., responsável pelo desencadeamento de uma onda de imigrantes japoneses especializados para compor seu quadro de técnicos.

Por último, cabe destacar a importância deste setor para o Estado do Rio de Janeiro, cuja história está para ser contada! Mesmo que, modestamente, acreditamos que instigamos a discussão sobre o assunto, de forma a propor a discussão sobre as relações travadas entre imigração, indústria naval e tecnologia nas terras fluminenses.

\section{Notas e Referências}

1 No caso do Estado do Rio de Janeiro, o tema da imigração tem atraído a atenção de estudiosos, assim como o interesse de jovens pesquisadores empenhados em preencher as lacunas e sobretudo revisar as teses gerais sobre a matéria, que ocultam as identidades local e regional.

2 Pedro Carlos da Silva TELLES. História da Engenharia Naval. Disponível na Internet. Cf. site http://www.transportes.gov.br/bit/estudos/Eng-naval/historia.htm 
3 O mais importante estaleiro do período, no entanto, situava-se na Bahia, o Arsenal de Marinha da Bahia fundado por Thomé de Souza, pois este Estado ficava posicionado na rota das embarcações da Carreira da Índia e era considerado estratégico no desenvolvimento da indústria naval. Esta supremacia durou até meados do século XIX.

4 Após a suspensão das proteções aduaneiras contra a concorrência estrangeira, um incêndio atingiu o estaleiro Ponta D’Areia e os negócios de Mauá decaíram.

5 Ryo SEKINE e Marileia Franco Marinho INOUE (org.). Cem anos de imigração japonesa no Estado do Rio de Janeiro, Comissão para Edição do Livro Comemorativo dos Cem Anos da Imigração Japonesa. São Paulo: Nippak Graphics, 2008, pp. 81-3.

6 Marcada pelo lançamento ao mar do Monitor Fluvial Parnaíba e uma série de seis navios mineiros da classe Carioca e três contratorpedeiros da classe Marcílio Dias, com estrutura soldada, sinal de progresso tecnológico naqueles dias; depois construíram seis contratorpedeiros da classe Amazonas e navios menores, entre eles o Argus, no final da década de 1950, cuja superestrutura era de alumínio com acabamento arrojado e marcado pelos grande blocos pré-fabricados.

7 Luisa Barbosa PEREIRA. Justa causa pro patrão!: a relação entre o sindicato dos metalúrgicos do Rio de Janeiro e a justiça no caso SERMETAL, Dissertação de Mestrado, Programa de Pós-Graduação em Sociologia e Antropologia da Universidade Federal do Rio de Janeiro, Fevereiro/2010, p 31.

8 Sucedido pelo seu filho Henrique Lage.

9 A história deste pioneiro, chegado ao Brasil em 1906, está relatada em Mariléia Franco Marinho INOUE. No Outro Lado Nasce o Sol: O Trabalho dos Japoneses e seus Descendentes no Estado do Rio de Janeiro. Universidade de São Paulo, Departamento de Sociologia, 2002, além de SEKINE e INOUE. Op. Cit., pp. 64-77. INOUE, 2002, Idem e SEKINE e INOUE, 2008, Idem, pp.102-103.

11 Yuzaburo Yamagata passou a pensão para seus ex-funcionários: Imakichi Kasajima, contramestre de marinha no Kasato Maru, que anteriormente já trabalhara no escritório da empresa marítima de Yamagata, no Japão e Hiroshi Imamura, que havia trabalhado em uma plantação em Macaé, no interior do Estado do Rio de Janeiro deram continuidade ao negócio recebendo cerca de 50 a 60 pessoas que ali dormiam.

12 Todos chegados no Ryojun Maru, em 1910, segundo navio a chegar ao Brasil com imigrantes.

13 R. SEKINE e M. F. M. INOUE. Op. Cit.

14 O costume japonês relacionado ao banho público, sem uso de roupa, custou aos imigrantes nipônicos, em várias partes do Estado, a reprovação por parte dos brasileiros que os consideravam despudorados. 
15 NHI Sirius foi incorporado à Marinha do Brasil em 13 de dezembro de 1957. O Navio-Hidrográfico Sirius foi especialmente projetado, construído e entregue oficialmente ao Brasil na cerimônia de mostra de armamento em 17 de janeiro de 1958, com missão de coletar e processar dados hidrográficos, oceanográfico e geodésicos, com finalidade de construir e atualizar cartas náuticas e documentos para a Diretoria de Hidrografia e Navegação. Contribui para a sinalização náutica e para os serviços metereológicos. Além de sua missão ainda dava apoio ao Posto Oceanográfico da Ilha de Trindade e possibilidade de estudos universitários.

16 Recebeu esse nome em 6 de junho de 1956 pelo Aviso n. ${ }^{o}$ 2023. Foi encomendado em 27 de abril de 1956, junto com o NHI Sirius H2. Foi lançado ao mar em 20 de novembro de 1957, tendo como madrinha a esposa de Ernesto de Melo Batista, presidente da Comissão Fiscal de Construção de Navios no Japão. Foi incorporado e submetido à Mostra de Armamento em 15 de março de 1958, em cerimônia realizada em Tóquio. Em 7 de janeiro, em cerimônia presidida pelo Chefe do Estado-Maior da Armada, foi realizada no molhe da Ilha Fiscal, foi submetido à Mostra de desarmamento e baixa do serviço ativo da Armada. Ao longo desses quase 39 anos de serviço, atingiu as marcas de 126 comissões hidrográficas, perfazendo um total de 3.342 dias de mar e 658.207 milhas navegadas. O ultimo cerimonial de arriar do Pavilhão Nacional foi realizado pelo Almirante Maximiano Eduardo da Silva Fonseca, juntamente com Neusa Feveret Matos, viúva do Almirante Rubem José Rodrigues de Matos, o primeiro Comandante do Navio.

17 Em dois de janeiro de 1959, foi feito o registro da Ishikawajima do BrasilEstaleiros S.A (ISHIBRÁS), com o capital de 99\% de participação da Ishikawajima Harima Heavy Industries. O primeiro Diretor-Presidente da empresa foi o Almirante Ayres Pinto da Fonseca Costa e o $1^{\circ}$ Vice-Presidente o Giroku Fujii, representante dos interesses do sócio japonês. Na parte jurídica do estaleiro estava o advogado Elbe Hayao e, no início de 1960, veio Takeo Ogino. Ainda na Diretoria estavam os japoneses Taiji Ubukata e I. Sawanobori. Os representantes do Brasil eram dois almirantes: o Diretor-Presidente Ayres Pinto da Fonseca Costa e Aniceto Cruz Santos, além do engenheiro civil Orlando Barbosa e Rubem Noronha. Entre os funcionários administrativos estavam Setsuko Nakano, que deixou a empresa para ser tradutora de japonês-português, o estagiário de direito Nakaguma, o funcionário Nakajima e o contabilista Yanase. Giroku Mitsui. na construção naval.

18 Construída em 1853 pelo Lorde Nariaki Tokugawa, na Ilha de Ishikawajima, situada na entrada do Rio Sumida que deságua na baía de Tóquio, se encontra em posição estratégia para a defesa costeira do Japão. 
19 Nas avaliaçôes dos funcionários contavam: idade, senso crítico, responsabilidade e, principalmente, o parecer favorável da chefia. A mão-de-obra brasileira aprendia rapidamente o ofício de soldagem, usinagem, montagem de peças e itens de manutenção ensinados pelos especialistas japoneses. Era estaleiro moderno, seja do ponto de vista da produção de navios seja do ponto de vista do suporte administrativo, transporte de pessoal, meios de comunicação e relacionamento com a Ishikawajima do Japão. Tinham várias Kombis, com o logotipo da ISHIBRÁS, todos os móveis e utensílios devidamente patrimoniados. A assistência jurídica era impecável: nos contratos firmados, a formação e manutenção de sociedade anônima, incorporação de bens importados e sem cobertura cambial para integrar o capital da sociedade. Era uma organização exemplar onde desde as obras de construção civil até setores de máquinas, equipamentos e motores gigantes tudo estava em pleno funcionamento.

Os diques secos eram destinados às edificações de navios, cujos trabalhos finais eram realizados junto ao cais. Depois de lançados, ocorriam os retoques finais. Era cavado no chão, com fortificação de aço construída e uma porta que se abria para o mar. Era o mais moderno dique seco do Brasil, com abertura para ingresso mecânico da água do mar, com o navio e escoamento fácil. Era uma grande construção, com telhados e laterais solidamente trabalhados, além de várias casas de suporte, onde os mecânicos e seus chefes se reuniam para estudar e orientar problemas. Do grande tanque seco abriam as comportas, os navios flutuavam e depois eram rebocados para o mar.

21 Opção mais barata para operações do dia-a-dia que o dique seco.

22300.000 toneladas deadweit

23 O navio tanque Marajó - G 27 foi ordenado em 1965, construído e entregue pela Ishikawajima do Brasil S/A, no Rio de Janeiro, lançado ao mar e batizado em 31 de janeiro de 1968 e incorporado à Armada da Marinha do Brasil em 8 de janeiro de 1969.

24 O navio tanque Almirante Gastão Mota G23 foi ordenado em 15 de dezembro de 1987, para substituir o Navio Tanque Marajó -G27 o Navio de Apoio logístico de mesmo nome-G29 (ex-NM Itatinga, do Lloyd Brasileiro), que teve a sua conversão cancelada, e foi vendido em 1987. Construído pela Ishikawajima do Brasil S/A, no Rio de Janeiro, foi lançado ao mar e batizado em 1 de junho de 1990 e incorporado à Armada da Marinha do Brasil em 26 de novembro de 1991.

25 O navio tanque Diva PPMY foi a primeira unidade de uma série de oito encomendados à Ishikawajima. . O navio teve como madrinha, em sua cerimônia de lançamento, Olga Ribeiro de Medeiros, esposa do então Chefe do Serviço Nacional de Informações (SNI). Segundo pesquisas feitas, identificamos: N/T Dilya PPNN, N/T Marta PPVH, N/T Nara PPVY e N/T Neusa PPWE, todos ainda ativos. 
volumes a granel, como soja, trigo, minérios, fertilizante, carvão, etc.., de acordo com as regras dos portos e rotas que devem operar, por isso variam bastante de tamanho e, devido a isso, tem uma nomenclatura especifica: Os navios supergraneleiros, $B W$ Fjord e o $B W V i k$ ( ex- DOCEFJORD e ex-TIJUCA) foram construídos no Brasil, em 1987, para DOCENAVE(CVRD). Cada um tem 310.698 toneladas e ambos pertencem, agora, ao mesmo armador norueguês BW(Bergesen), maior beneficiado com o fim da Docenave. Foi renomeado em 2000 para Berge Fjord e nomeado BW Fjord em 2007.

Possivelmente em homenagem ao navio de mesmo nome torpedeado na I Grande Guerra mundial pelos alemães, perto da costa francesa, o que determinou a entrada do Brasil na Guerra e o confisco de 42 navios alemães que estavam em portos brasileiros, como indenização de Guerra. metalúrgicos do Rio de Janeiro e a justiça no caso SERMETAL, Dissertação de Mestrado, Programa de Pós-Graduação em Sociologia e Antropologia da Universidade Federal do Rio de Janeiro, Fevereiro/2010, p 31. metalúrgicos do Rio de Janeiro e a justiça no caso SERMETAL. Rio de Janeiro, Universidade Federal do Rio de Janeiro, Programa de Pós-Graduação em Sociologia e Antropologia: Dissertação de Mestrado, fevereiro de 2010, p. 37. (PEREIRA, 2006:37-38).

39 Equipamentos e Características do Estaleiro: Área das oficinas (coberta): $16.550 \mathrm{~m}^{2}$ (oficinas de caldeiraria, tubulação, estrutural e usinagem); Dique no 1: $155 \mathrm{~m}$ de comprimento; $25 \mathrm{~m}$ de largura; calado máximo $3,80 \mathrm{~m}$; capacidade para navios de até $10.000 \mathrm{TPB}$; Dique no 2: 350m de comprimento; $65 \mathrm{~m}$ de largura; calado máximo 6,20m; capacidade para Navios de até $400.000 \mathrm{TPB}$; Guindastes: 1 x 300t, 1 x 200t, 1 x 100t, 2 x 40t e 1 x 20t; Pontes rolantes: Várias, de 5t até 50t; Cais de acabamento 1 e 2: 293m de comprimento; calado máximo 6m; Cais de acabamento no 3: 45m de comprimento; calado máximo 
8m; Cais de acabamento no 4: 286m de comprimento; calado máximo 8m.Fonte: http://www.portalnaval.com.br/estaleiros-no-brasil.

40

O grupo empresarial de Nelson Tanure anexou ao seu patrimônio, em 1991, o estaleiro VEROLME de Angra dos Reis e o EMAQ, atual EISA, da Ilha do Governador. Os japoneses transferiram seu estaleiro, que passou a ser denominado indústria Verolme Ishibrás S/A - Caju (IVI Caju). Posteriormente Tanure repassou o estaleiro de Angra para o Grupo Jurong de Cingapura e o EMAQ para Manuel Ribeiro, empresário do ramo. 